\title{
NATURAL RADIOACTIVITY AND RADIOLOGICAL RISK PARAMETERS IN LOCAL AND IMPORTED BUILDING MATERIALS USED IN SUDAN
}

\author{
AdREANI, T. E. ${ }^{1,2}$ - MATtAR, E. ${ }^{2}$ - AlsAFI, K. ${ }^{3}$ - SUliemAn, A. ${ }^{4}-$ SUliman, I. I. ${ }^{1,5^{*}}$ \\ ${ }^{1}$ Sudan Atomic Energy Commission, Radiation Safety Institute, P.O. Box 3001, Khartoum, \\ Sudan \\ ${ }^{2}$ Department of Radiological Sciences, College of Applied Medical Sciences, King Saud \\ University, P.O Box 10219, Riyadh 11433, Saudi Arabia \\ ${ }^{3}$ Department of Radiology, Medical Physics Unit, King Abdul Aziz University, P.O. Box 80215, \\ Jaddah 21589, Kingdom of Saudi Arabia \\ ${ }^{4}$ Prince Sattam bin Abdulaziz University, College of Applied Medical Sciences, Radiology and \\ Medical Imaging Department, Alkharj, Kingdom of Saudi Arabia \\ ${ }^{5}$ Imam Mohammad Ibn Saud Islamic University (IMSIU), Department of Physics, College \\ of Science, Riyadh 11642, Saudi Arabia \\ *Corresponding author \\ e-mail: i.i.suliman@gmail.com; phone: +96-653-891-8127 \\ (Received 22 $2^{\text {nd }}$ Apr 2020; Accepted 16 ${ }^{\text {th }}$ Sep 2020)
}

\begin{abstract}
Natural radioactivity levels in selected types of building materials used in Sudan were measured using gamma spectrometry. Radioactivity concentrations were measured in 52 samples including cements, porcelain ware, and ceramic tiles, cement blocks, and red clay bricks. Representative samples were powdered and stored in polyethylene Marinelli containers for four weeks to attain equilibrium between ${ }^{226} \mathrm{Ra}$ and ${ }^{232} \mathrm{Th}$ and their daughters before measurements. The average radioactivity $\left(\mathrm{Bq} \cdot \mathrm{kg}^{-1}\right)$ of ${ }^{226} \mathrm{Ra}$, ${ }^{232} \mathrm{Th}$, and ${ }^{40} \mathrm{~K}$, ranged between $12-40,10-70$, and $28-94$, respectively in cement; 10-35, 12-28, and 87-143, respectively in cement blocks; 32-132, 26-87, and 285-1070, respectively in red bricks; and 8-527, 18-118, and 129-812, respectively in ceramics and porcelain tiles. The air absorbed dose rates ranged between $12.0 \pm 3.0$ to $40.5 \pm 23.0 \mathrm{nGyh}^{-1}$ in materials used in a superficial amount; $34.4 \pm 8.9$ to $173.3 \pm 52.0 \mathrm{nGyh}^{-1}$ in materials used in bulk. The annual effective doses were varied from 0.06 to $0.85 \mathrm{mSv}$. Excluding porcelain ware samples. The activity concentration indexes describing external and internal radiation hazards were within the acceptable limits. The study provides important baseline data for setting national regulatory control limits for protection against radiation.
\end{abstract}

Keywords: gamma spectrometry, cements and bricks, gamma index, indoor radiation hazards

\section{Introduction}

Building materials contain naturally occurring radioactive materials (NORM) due to the natural radionuclide content in their raw materials or due to the additives used in the manufacturing process, such as zircon sand which contains traces of uranium and thorium and constitutes the radioactive content in ceramic and tiles (IAEA, 2003). The radiological risk from external radiation exposure due to natural radioactivity in building materials is caused by terrestrial gamma radiation from ${ }^{226} \mathrm{Ra},{ }^{232} \mathrm{Th}$, and ${ }^{40} \mathrm{~K}$ NORM as well as the internal exposure from radon (EC, 1999; UNSCEAR, 2000; Righi and Bruzzi, 2006). Radon in building materials is the major cause of the incidence of fatal cancer in the global population (ICRP, 2019). 
Bearing in mind that certain levels of radiation exposures due to radioactive contents in building materials is inevitable, international radiation protection advisory bodies assert radiation exposure be kept as low as reasonably possible. As people spend nearly $80 \%$ of their time indoors, the main motive of radiological studies of building materials has been to limit public radiation exposure due to the natural radioactivity of the constituents of these materials.

Sudan is one of the largest countries in Africa where houses are built using stones and other local materials that are characterized by the local geological sands. This diversity of materials makes it difficult to study samples of materials used all over the country. We found only two studies on this subject. One is by Sam and Abbas (2001), who reported radioactivity in local and imported cement types used in Sudan. The other is by Salih et al. (2014), who studied the radiation exposure of workers in storage areas for building materials. Due to the dynamic nature of the construction industry, the issue of radioactivity in building materials remains an open question.

In this study, we aim to provide a comprehensive survey of radioactivity present in local and imported building materials in Sudan and its impact on the exposure of the public to radiation. Further, we aim to provide up-to-date information on this subject to assist institutions in formulating regulations on the national level to control radiation.

\section{Materials and Methods}

\section{Sampling}

In total, 52 samples of local and imported building materials of widely distributed origins were collected from stores in the Sudanese capital, Khartoum. A radioactivity measurement in building materials is important for radiation protection purposes. Representative samples of building materials were powdered and stored in polyethylene Marinelli containers for four weeks to allow equilibrium between ${ }^{226} \mathrm{Ra}$ and ${ }^{232} \mathrm{Th}$ and their daughters to be reached.

\section{Measurements of radioactivity}

Sample specific activities were determined using the p-type high purity germanium (HPGe) gamma spectrometry with $30 \%$ relative efficiency to (NaI)Tl gamma spectroscopy for $1.33 \mathrm{MeV}{ }^{60} \mathrm{Co}$ radiation of 122 and $1332 \mathrm{keV}$ gamma line of 0.875 and $1.850 \mathrm{keV}$, respectively (Baltic Instrument, Riga, Latvia). Energy and efficiency calibrations were performed using a mixed radionuclide gamma calibration standard (Amersham Buchler B1575). For the radioactivity quantifications, ${ }^{226} \mathrm{Ra}$ activities were determined from ${ }^{214} \mathrm{~Pb}(351.92 \mathrm{keV})$ and ${ }^{214} \mathrm{Bi}(609.31 \mathrm{keV})$. The gamma energy lines of ${ }^{212} \mathrm{Bi},{ }^{212} \mathrm{~Pb}$, and ${ }^{228} \mathrm{Ac}$ were used to determine the ${ }^{232} \mathrm{Th}$ activity. The radioactivity of ${ }^{40} \mathrm{~K}$ was determined from the $1460.81 \mathrm{keV}$ gamma line (IAEA, 2003). The activity concentration (A) in $\mathrm{Bqkg}^{-1}$ in samples was calculated using the following expression:

$$
A=\frac{N}{P E \times \mathcal{E} \times T c \times M}
$$

where, $M$ denotes the mass of sample in $\mathrm{kg}, N$ the sample net area in the peak, $P E$ the gamma emission probability, Tc the counting time, and $\mathcal{E}$ denotes the photopeak efficiency. Uncertainty in the activity concentration was determined at a $95 \%$ confidence level $(\sigma=2)$ using eq. (2): 


$$
\frac{u\left(C_{s p}\right)}{C_{s p}}=\sqrt{\left(\frac{u(N)}{N}\right)^{2}+\left(\frac{u\left(P_{E}\right)}{P_{E}}\right)^{2}+\left(\frac{u(\varepsilon)}{\varepsilon}\right)^{2}+\left(\frac{u\left(T_{C}\right)}{T_{C}}\right)^{2}+\left(\frac{\Delta M}{M}\right)^{2}}
$$

where, $\frac{u(N)}{N}, \frac{u\left(P_{E}\right)}{P_{E}}, \frac{u(\varepsilon)}{\mathcal{E}}, \frac{u\left(T_{C}\right)}{T_{C}}$, and $\frac{\Delta M}{M}$ are the relative uncertainties in the counting rate, gamma emission probability, photopeak efficiency, counting time, and sample mass, respectively. Uncertainty in the activity concentration was determined by the SpectraLineGP software at $1 \sigma$ (Baltic Instrument, Riga, Latvia). The overall uncertainty in the determined activity was the square root of the quadratic sum of different activity parameters at a $95 \%$ confidence level $(\sigma=2)$ according to the ISO standard (ISO, 1995).

\section{Radium equivalent activity (Raeq)}

In comparing radioactivity amounts in different samples, the radium equivalent activity ( $\left.\mathrm{Ra}_{\mathrm{eq}}\right)$ is used (Beretka and Mathew, 1985). $\mathrm{Ra}_{\mathrm{eq}}$ represents the combined specific activities of ${ }^{226} \mathrm{Ra},{ }^{232} \mathrm{Th}$, and ${ }^{40} \mathrm{~K}$ and determined according to the following formula:

$$
R a_{e q}=A_{R a}+1.43 A_{t h}+0.077 A_{K}
$$

where, $\mathrm{A}_{\mathrm{Ra}}, \mathrm{A}_{\mathrm{Th}}$, and $\mathrm{A}_{\mathrm{K}}$ are the specific activity of ${ }^{226} \mathrm{Ra},{ }^{232} \mathrm{Th}$, and ${ }^{40} \mathrm{~K}$, respectively.

\section{Air absorbed dose rates}

The indoor gamma absorbed dose rates in the air arising from radioactivity in building materials can be estimated using the radionuclide-specific dose rates conversion coefficients ( $\mathrm{nGy} \mathrm{h}^{-1}$ per Bq kg${ }^{-1}$ ). For materials of superficial use, such as ceramic and porcelain tiles, absorbed dose rates are determined as (EC, 1999):

$$
D=0.12 . C_{R a}+0.14 . C_{T h}+0.0096 . C_{K}
$$

For bulk use materials such as concrete and red brick, absorbed dose rates are determined as (EC, 1999):

$$
D=0.92 . C_{R a}+1.1 . C_{T h}+0.08 . C_{K}
$$

\section{Effective doses}

The effective dose is an important dosimetry quantity to estimate radiation risk. It facilitates comparison among different exposure categories. According to UNSCEAR (2000), a value of $0.7 \mathrm{~Sv} / \mathrm{Gy}$ absorbed dose to effective dose conversion coefficient and 0.8 as an indoor occupancy factor. Therefore, an effective dose can be determined from air absorbed dose rates as follows:

$$
E\left(S v y^{-1}\right)=D\left(n G y h^{-1}\right) \cdot 8760 h y^{-1} \cdot 0.8 \cdot 0.7 S v G y^{-1} \cdot 10^{-3}
$$

\section{The gamma indexes}

The gamma index $\left(I_{\gamma}\right)$ is an important single quantity used in determining whether the external absorbed dose originating from radioactive content in building materials are 
within the recommended annual dose limit for the public (EC, 1999): $I_{\gamma}$ is determined from the respective radioactivity of the three natural radionuclides as follows:

$$
I_{\gamma}=\frac{C_{T h}}{200 B q / k g}+\frac{C_{R a}}{300 B q / k g}+\frac{C_{K}}{3000 B q / k g}
$$

where, $\mathrm{C}_{\mathrm{Ra}}, \mathrm{C}_{\mathrm{Th}}$, and $\mathrm{C}_{\mathrm{K}}$ are the radioactivity of ${ }^{226} \mathrm{Ra},{ }^{232} \mathrm{Th}$, and ${ }^{40} \mathrm{~K}$, respectively.

\section{Alpha index $\left(I_{\alpha}\right)$}

This is another parameter used in estimating the internal radiation exposure attributed to radon from uranium isotopes in building materials. With $\mathrm{A}_{\mathrm{Ra}}$ being radioactive $\left(\mathrm{Bq} \cdot \mathrm{kg}^{-1}\right.$ ) of ${ }^{226} \mathrm{Ra}, I_{\alpha}$, is defined as follows (Righi and Bruzzi, 2006):

$$
I_{\alpha}=\frac{A_{R a}}{200 B q \cdot k g^{-1}}
$$

Building materials with $I_{\alpha}<1$ corresponding to radium radioactivity of 200 (Bq. $\mathrm{kg}^{-1}$ ) are considered safe for building constructions (NORDIC, 2000). The gamma index $\left(I_{\gamma}\right)$ and alpha index $\left(I_{\alpha}\right)$ represent the levels to which the annual dose must be limited. The limits are summarised in Table 1.

Table 1. The gamma index $\left(I_{\gamma}\right)$ and alpha index $\left(I_{\alpha}\right)$ limits to achieve the recommended

\begin{tabular}{|c|c|c|}
\hline Dose criterion & $0.3 \mathrm{mSv} / \mathrm{y}$ & $1 \mathrm{mSv} / \mathrm{y}$ \\
\hline \multicolumn{3}{|l|}{ Activity concentration index $\left(I_{\gamma}\right)$} \\
\hline $\begin{array}{l}\text { Materials used in bulk amount: Concrete, red bricks } \\
\text { Materials used in ssuperficial amount: porcelain and ceramic tiles }\end{array}$ & $\begin{array}{l}\mathrm{I} \leq 0.5 \\
\mathrm{I} \leq 2\end{array}$ & $\begin{array}{l}\mathrm{I} \leq 1 \\
\mathrm{I} \leq 6\end{array}$ \\
\hline \multicolumn{3}{|l|}{ Alpha index $\left(I_{\alpha}\right)$} \\
\hline All building materials & & $\mathrm{I} \leq 1$ \\
\hline
\end{tabular}
annual dose limits

\section{Statistical analysis}

The statistical analysis has been carried out using Pearson correlation and was considered significant at $\mathrm{P}$-value $<0.05$, which indicates strong evidence against the null hypothesis.

\section{Results and Discussion}

Natural radioactivity and radiological risk parameters were measured on 52 types of local and imported building materials used in Sudan. Table 2 shows the type of building materials, their uses, and their countries of origin.

\section{Radioactivity and radium equivalent activity (Raeq)}

Table 3 presents the statistical summary of radioactivity concentrations in selected building materials used in Sudan. The boxplot distribution of activity concentrations ${ }^{226} \mathrm{Ra}$, ${ }^{232} \mathrm{Th}$, and ${ }^{40} \mathrm{~K}$ natural radionuclides is shown in Fig. 1. As shown, mean ${ }^{226} \mathrm{Ra}$ activity concentrations ranged from 31.6-131.7 Bq. $\mathrm{kg}^{-1}$ in red bricks to $228.4 \pm 172.6 \mathrm{~Bq} \cdot \mathrm{kg}^{-1}$ in Italian porcelain (IP), whereas the mean ${ }^{232} \mathrm{Th}$ activity 
concentrations of ${ }^{232} \mathrm{Th}$ ranged from $6.2 \pm 2.0$ (SC) to $82.8 \pm 20.3 \mathrm{~Bq} \mathrm{~kg}^{-1}$ in (CP). For ${ }^{40} \mathrm{~K}$, average activity concentration ranged from $62.2 \pm 27.1$ (SC) to $721.6 \pm 319.5$ in red bricks from Sudan. The considerable variation in activity concentrations may be ascribed to the raw materials and industrial by-products of present building materials, as these replicate the geological characteristics of the sites of their origin.

Table 2. Distribution of building materials, their uses, and the country of origin

\begin{tabular}{c|c|c|c|c}
\hline Code & Type & Uses & Sample size & Country of origin \\
\hline PC & Tiles (Porcelain) & Superficial & 5 & China \\
CC & Tiles (Ceramic) & Superficial & 8 & China \\
PI & Tiles (Porcelain) & Superficial & 7 & Italy \\
CE & Tiles (Ceramic) & Superficial & 4 & Egypt \\
TS & Tiles (Ceramic) & Superficial & 6 & Sudan \\
CS & Cement & Superficial/Bulk & 10 & Sudan \\
BC & Concrete block & Bulk & 6 & Sudan \\
RB & Red brick & Bulk & 6 & Sudan \\
\hline
\end{tabular}

Table 3. Statistical summary of the activity concentration and radium equivalent activity $\left(B q . \mathrm{kg}^{-1}\right)$ for ${ }^{226} \mathrm{Ra},{ }^{232} \mathrm{Th},{ }^{40} \mathrm{~K}$ in selected types of building materials used in Sudan

\begin{tabular}{c|c|c|c|c|c|c|c|c}
\hline \multirow{2}{*}{ Type } & \multicolumn{2}{c|}{ ARa } & \multicolumn{2}{c|}{ ATh } & \multicolumn{2}{c}{ AK } & \multicolumn{2}{c}{ Raeq } \\
\cline { 2 - 9 } & Mean & Range & Mean & Range & Mean & Range & Mean & Range \\
\hline \multicolumn{8}{c}{ Materials used in superficial amount } \\
\hline ST & 22.9 & $7.9-29.8$ & 28.2 & $17.5-38.6$ & 662.1 & $438.5-812.5$ & 114.2 & $83.1-128.3$ \\
CC & 48.2 & $19.3-84.6$ & 32.6 & $22.2-41.1$ & 169.4 & $129.4-238.9$ & 107.9 & $79.3-161.8$ \\
CP & 158.5 & $87.6-215.2$ & 82.8 & $59.0-113.4$ & 489.8 & $378.4-607.3$ & 314.6 & $23.8-41.9$ \\
IP & 228.4 & $78.3-526.8$ & 69.9 & $41.5-101.6$ & 346.5 & $238.9-428.1$ & 355.1 & $159.2-646.0$ \\
EC & 58.0 & $47.2-69.2$ & 53.7 & $33.1-80.4$ & 398.3 & $262.4-515.5$ & 165.4 & $129.8-209.0$ \\
\hline \multicolumn{8}{c}{ Materials used in bulk amount } \\
\hline SC & 24.6 & $12.0-39.6$ & 6.2 & $1.4-8.7$ & 62.8 & $28.1-93.7$ & 38.2 & $21.3-51.6$ \\
BC & 23.1 & $9.8-35.0$ & 21.9 & $11.7-28.0$ & 108.8 & $87.0-143.0$ & 62.7 & $34.4-86.1$ \\
RB & 63.9 & $31.6-131.7$ & 51.6 & $25.8-86.9$ & 721.6 & $284.5-1070.0$ & 193.3 & $120.2-290.8$ \\
\hline
\end{tabular}

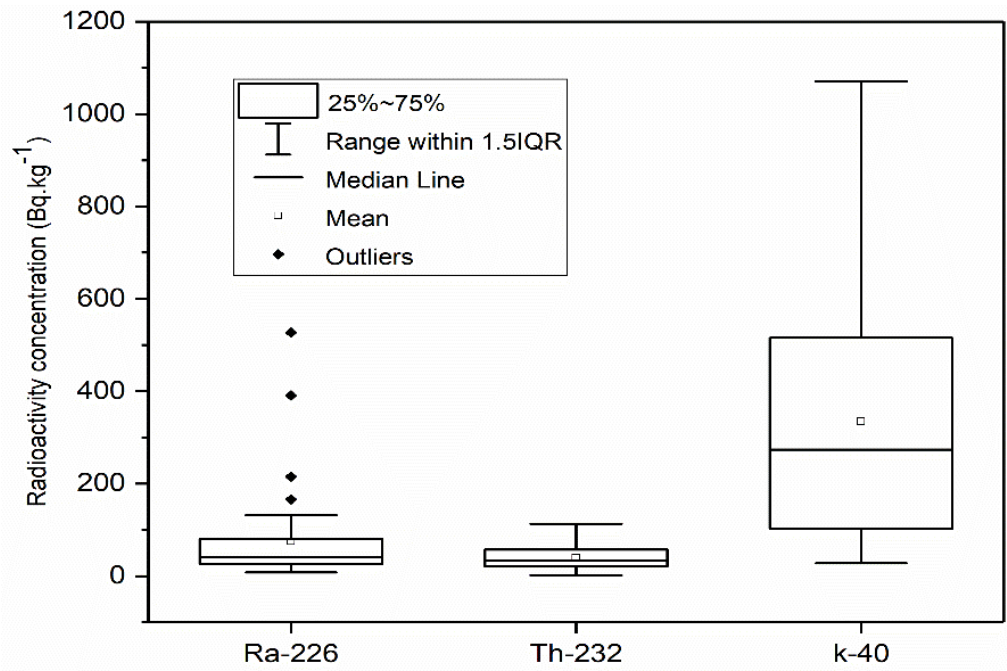

Figure 1. Boxplot distribution of activity concentrations ${ }^{226} \mathrm{Ra},{ }^{232} \mathrm{Th}$ and ${ }^{40} \mathrm{~K}$ natural radionuclides showing the interquartile range (IQR)(25th to 75 th percentile), the range within 1.5IQR, the median and the mean lines and the outliers 
Of particular interest is the high radioactivity content of the porcelain samples (CP \& IP), which show radioactivity approximately one order of magnitude higher than other subjects. Despite their high radioactivity content, as porcelain is used superficially and in small amounts, their relevant radiological risk is expected to be low as compared to other materials that are used in bulk amount. Elevated radioactivity of porcelain samples is related to their zirconium silicate content known for its high natural radionuclide content (IAEA, 2003).

In conformity with the previous observations, the average activity concentrations in building materials obtained in this study and reported in the literature are higher than those found in the earth's crust, being 35, 30, and $400 \mathrm{~Bq} \cdot \mathrm{kg}^{-1}$ of ${ }^{226} \mathrm{Ra},{ }^{232} \mathrm{Th}$, and ${ }^{40} \mathrm{~K}$, respectively (UNSCEAR, 2000).

The activity concentrations of natural radionuclides ${ }^{226} \mathrm{Ra},{ }^{232} \mathrm{Th}$, and ${ }^{40} \mathrm{~K}$ are not uniform in a given sample, which necessitates setting of a single parameter to represent the total radioactivity, the radium equivalent activity, to be used for comparing the specific activity of materials containing different amounts of ${ }^{226} \mathrm{Ra},{ }^{232} \mathrm{Th}$ and ${ }^{40} \mathrm{~K}$. The human body treats radium in a similar way to calcium accumulating in human body bones resulting in internal exposure that could cause bone cancer considered to be among the most common radiation cacogenics (NRC, 1988).

As observed in Table 3, $\mathrm{Ra}_{\mathrm{eq}}$ values ranged from $22.9 \pm 7.9$ to $355.1 \pm 195.1 \mathrm{~Bq} \cdot \mathrm{kg}^{-1}$. These values fall below the maximum permissible value of $370 \mathrm{~Bq} / \mathrm{kg}$ (UNSCEAR, 2000).

Table 4 shows the comparison of activity concentrations (Bq. $\mathrm{kg}^{-1}$ ) in building materials obtained in this study with those found in the literature. As seen, the activity concentrations in cement found in this study are comparable with or below those observed in previous studies performed in Jordan, Turkey by IAEA and EC (EC, 1999; IAEA, 2003; Mavi and Akkurt, 2010; Salih et al., 2014; Shayeb et al., 2017). The activity concentrations in porcelain and ceramic tiles used in small amounts are comparable with or higher than those reported in the literature.

As portrayed in Table 4, there exist wide differences between radioactivity in building materials in our study and those reported by Salih et al. (2014); this could be ascribed to differences in the origin of the studied building materials and this emphasises the importance of regular monitoring radioactivity levels in the materials used for building construction to ensure the safety of the occupants.

\section{Radiation doses}

The indoor dose rates from ${ }^{226} \mathrm{Ra},{ }^{232} \mathrm{Th}$, and ${ }^{40} \mathrm{~K}$ in building materials used in this study (excluding red brick) ranged from 12.0-173.0 $\mathrm{nGyh}^{-1}$ (Table 5). The determined absorbed doses are comparable to the world average for areas having normal background radiation $\left(55 \mu \mathrm{Gyh}^{-1}\right)$ (UNSCEAR, 2000). The obtained average annual effective dose values ranged from 0.06 to $0.85 \mathrm{mSv}$ and are, therefore, below the annual dose limit for the public $(1.0 \mathrm{mSv})$.

\section{Radiological risk parameters}

The radiological risk to an individual from radioactivity content in building materials is better described using gamma index, $I_{\gamma}$ for external exposure and the alpha index $\left(I_{\alpha}\right)$ for internal exposure to radon. $I_{\gamma}$ and $I_{\alpha}$ index limits prescribed for achieving the recommended annual dose limits are summarised in Table 1 (EC, 1999). 
Table 4. Comparison of activity concentrations $\left(B q . \mathrm{kg}^{-1}\right)$ in building materials obtained in this study with the literature

\begin{tabular}{|c|c|c|c|c|}
\hline Country & $\mathbf{A}_{\mathbf{R a}}$ & $\mathbf{A}_{\text {Th }}$ & $\mathbf{A}_{\mathbf{K}}$ & Reference \\
\hline Soil, world average & 35 & 30 & 400 & UNSCEAR (2000) \\
\hline \multicolumn{5}{|c|}{ Cement uses in bulk and superficial amount } \\
\hline Turkey & 26 & 10 & 130 & Mavi and Akkurt (2010) \\
\hline Sudan & 15 & 33 & 230 & Salih et al. (2014) \\
\hline Jordan & $37-121$ & $54-142$ & $255-621$ & Shayeb et al. (2017) \\
\hline IAEA & $7-180$ & $7-240$ & $24-850$ & IAEA (2003) \\
\hline $\begin{array}{l}\text { European } \\
\text { Community }\end{array}$ & $50(25-87)$ & $35(10-70)$ & $235(38-587)$ & Trevisi et al. (2018) \\
\hline Sudan & $25(12 \pm 40)$ & $6.1(1.4-8.7)$ & $63(28-94)$ & This study \\
\hline \multicolumn{5}{|c|}{ Cement block uses in bulk } \\
\hline Sudan & $11.5 \pm 1.4$ & $14.98 \pm 1.4$ & $378.37 \pm 42.0$ & Salih et al. (2014) \\
\hline $\begin{array}{l}\text { European } \\
\text { Community }\end{array}$ & $59(14-272)$ & $34(5-138)$ & $340(17-685)$ & Trevisi et al. (2018) \\
\hline IAEA & $1-250$ & $1-190$ & $5-1570$ & IAEA (2003) \\
\hline Sudan & $23(10-35)$ & $22(12-28)$ & $109(87-143)$ & This study \\
\hline \multicolumn{5}{|c|}{ Red brick uses in bulk } \\
\hline Turkey & 58.9 & 11.7 & 248.8 & Mavi and Akkurt (2010) \\
\hline Sudan & $20.4 \pm 2.1$ & $58.1 \pm 3.1$ & $459.6 \pm 116.8$ & Salih et al. (2014) \\
\hline Jordan & $13-19$ & $55-63$ & $160-202$ & Shayeb et al. (2017) \\
\hline IAEA & $1-200$ & $1-200$ & $60-2000$ & IAEA (2003) \\
\hline $\begin{array}{l}\text { European } \\
\text { Community }\end{array}$ & $51(7-84)$ & $49(4-102)$ & $555(59-805)$ & Trevisi et al. (2018) \\
\hline Sudan & $64(32-132)$ & $52(26-87)$ & $722(285-1070)$ & This study \\
\hline \multicolumn{5}{|c|}{ Tiles /Porcelains/Ceramics used in superficial amount } \\
\hline Italy & 84 & 54 & 609 & Righi et al. (2009) \\
\hline Turkey & 97 & 68 & 471 & Turban et al. (2013) \\
\hline Sudan & 31 & 60 & 486 & Salih et al. (2014) \\
\hline IAEA & $30-200$ & $20-200$ & $160-1410$ & IAEA (2003) \\
\hline Sudan & $105(8-527)$ & $52(18-118)$ & $393(129-812)$ & This study \\
\hline
\end{tabular}

Table 5. Statistical summary of doses and the radiological hazard parameters: $D\left(n G y h^{-1}\right)$, $E\left(m S v y^{-1}\right), I_{\gamma}$ and $I_{\alpha}$ estimated from the radioactivity concentrations in building materials used in Sudan

\begin{tabular}{c|c|c|c|c|c|c|c|c}
\hline \multirow{2}{*}{ Type } & \multicolumn{2}{c|}{ D (nGyh-1) } & \multicolumn{2}{c|}{ E $(\mathbf{m S v y - 1})$} & \multicolumn{2}{c|}{$\boldsymbol{I}_{\gamma}$} & \multicolumn{2}{c}{$\boldsymbol{I}_{\boldsymbol{\alpha}}$} \\
\cline { 2 - 8 } & Mean & Range & Mean & Range & Mean & Range & Mean & Range \\
\hline \multicolumn{8}{|c}{ Materials used in superficial amount } \\
\hline ST & 13.1 & $9.7-14.7$ & 0.06 & $0.05-0.07$ & 0.43 & $0.32-0.49$ & 0.57 & $0.42-0.64$ \\
CC & 12.0 & $8.5-18.2$ & 0.06 & $0.04-0.09$ & 0.41 & $0.26-0.64$ & 0.54 & $0.40-0.81$ \\
CP & 35.3 & $23.8-41.9$ & 0.17 & $0.12-0.21$ & 1.23 & $0.81-1.50$ & 1.57 & $1.06-1.85$ \\
IP & 40.5 & $17.9-75.7$ & 0.20 & $0.09-0.37$ & 1.49 & $0.63-2.97$ & 1.78 & $0.80-3.23$ \\
EC & 18.3 & $14.6-22.7$ & 0.09 & $0.07-0.11$ & 0.60 & $0.51-0.71$ & 0.83 & $0.65-1.04$ \\
\hline \multicolumn{8}{c}{ Materials used in bulk amount } \\
\hline SC & 34.4 & $20.2-46.3$ & 0.17 & $0.10-0.23$ & 0.16 & $0.10-0.23$ & 0.19 & $0.11-0.26$ \\
BC & 54.0 & $30.1-74.4$ & 0.27 & $0.15-0.37$ & 0.22 & $0.12-0.32$ & 0.31 & $0.17-0.43$ \\
RB & 173.3 & $111.1-253.0$ & 0.85 & $0.55-1.24$ & 0.73 & $0.47-1.10$ & 0.97 & $0.60-1.45$ \\
\hline
\end{tabular}


For ceramics and tiles used in a superficial amount, mean $I_{\gamma}$ values ranged from 0.41 to 1.49 and are less than 2 , which corresponds with the annual dose limit of $0.3 \mathrm{mSv}$. These materials can be exempted from regulatory control. For the cement blocks and red bricks, which materials are used in bulk amount, $I_{\gamma}$ values ranged from 0.16 to 0.73 . These materials exceed the lower limit of $I_{\gamma}$ and, therefore, need to be subjected to regulatory control. As presented in Table $4, I_{\alpha}$ for CP \& IP porcelain was $1.57 \pm 0.37$ and $1.78 \pm 0.98$, respectively. These levels exceed the prescribed limit of $<1$ indicating that the use of this imported decorative material poses risk to the safety of the occupants.

\section{Correlations between ${ }^{226} \mathrm{Ra},{ }^{232} \mathrm{Th}$ and ${ }^{40} \mathrm{~K}$ activities}

Table 6 shows the Pearson correlation coefficients of ${ }^{226} \mathrm{Ra},{ }^{232} \mathrm{Th}$, and ${ }^{40} \mathrm{~K}$ radionuclides. The results are graphically depicted in Fig. 2 and Fig. 3. A significant correlation was observed between ${ }^{232} \mathrm{Th}$ and ${ }^{40} \mathrm{~K}(\mathrm{R}=0.42, \mathrm{P}<0.05)$; and a highly significant correlation was observed between ${ }^{226} \mathrm{Ra}$ and ${ }^{232} \mathrm{Th}(\mathrm{R}=0.68, \mathrm{P}<0.001)$. The correlations observed could be due to the raw materials and industrial by-product of the building materials being of the same origin.

Table 6. Pearson correlation coefficients between ${ }^{226} \mathrm{Ra},{ }^{232} \mathrm{Th}$, and ${ }^{40} \mathrm{~K}$

\begin{tabular}{c|c|c|c|c|c|c}
\hline \multirow{2}{*}{ Radionuclide } & \multicolumn{2}{|c|}{${ }^{226} \mathbf{R a}$} & \multicolumn{2}{c|}{${ }^{232} \mathbf{T h}$} & \multicolumn{2}{c}{${ }^{\mathbf{4 0}} \mathbf{K}$} \\
\cline { 2 - 7 } & $\begin{array}{c}\text { Pearson } \\
\text { corr. }\end{array}$ & p-value & $\begin{array}{c}\text { Pearson } \\
\text { corr. }\end{array}$ & p-value & $\begin{array}{c}\text { Pearson } \\
\text { corr. }\end{array}$ & p-value \\
\hline${ }^{226} \mathrm{Ra}$ & 1 & $* *$ & $0.68 *$ & $<0.001$ & 0.15 & 0.28 \\
${ }^{232} \mathrm{Th}$ & $0.68 *$ & $<0.001$ & 1 & $* *$ & $0.42 *$ & 0.002 \\
${ }^{40} \mathrm{~K}$ & 0.15 & 0.28 & $0.42^{*}$ & 0.002 & 1 & $* *$ \\
\hline
\end{tabular}

Correlation significant at $\mathrm{p}<0.05$; and highly significant at $\mathrm{p}<0.001$

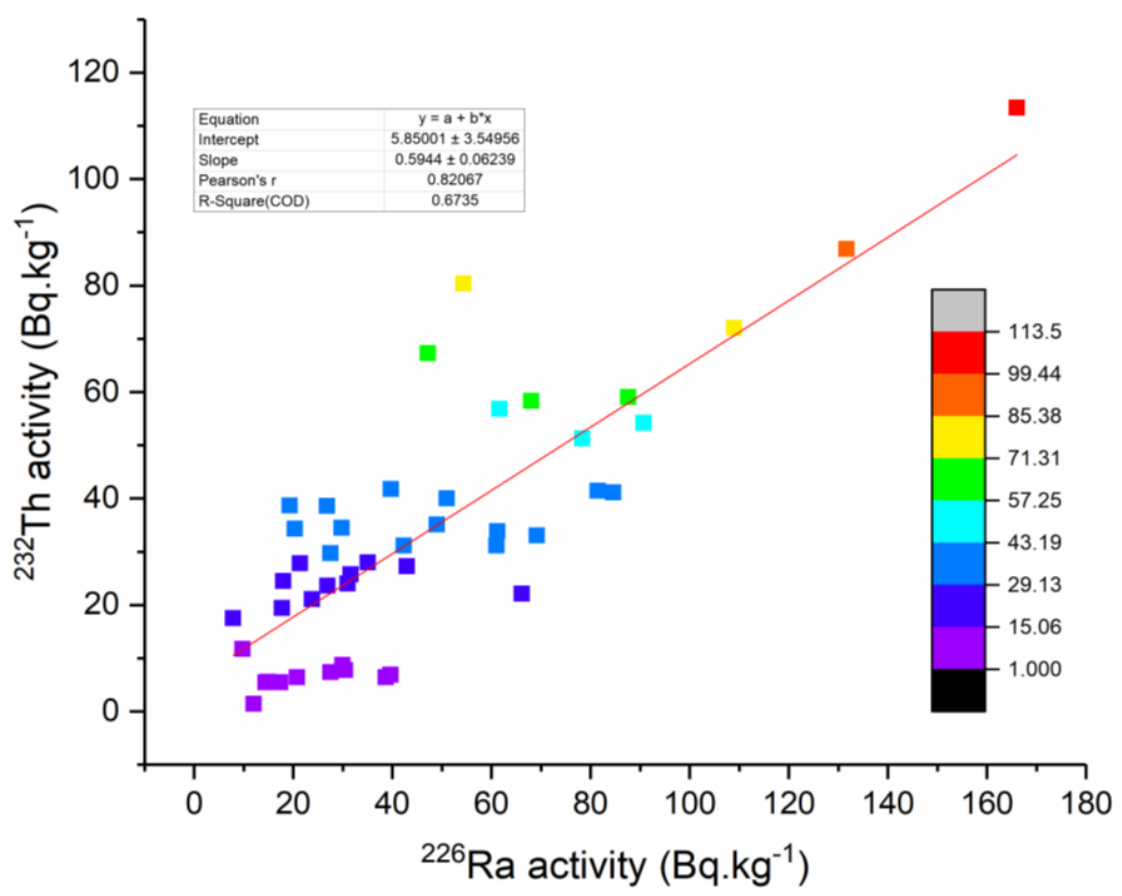

Figure 2. Correlation between of activity concentrations ${ }^{226} \mathrm{Ra}$ and ${ }^{232}$ Th natural radionuclides showing colour codes for the corresponding ${ }^{232}$ Th activity 


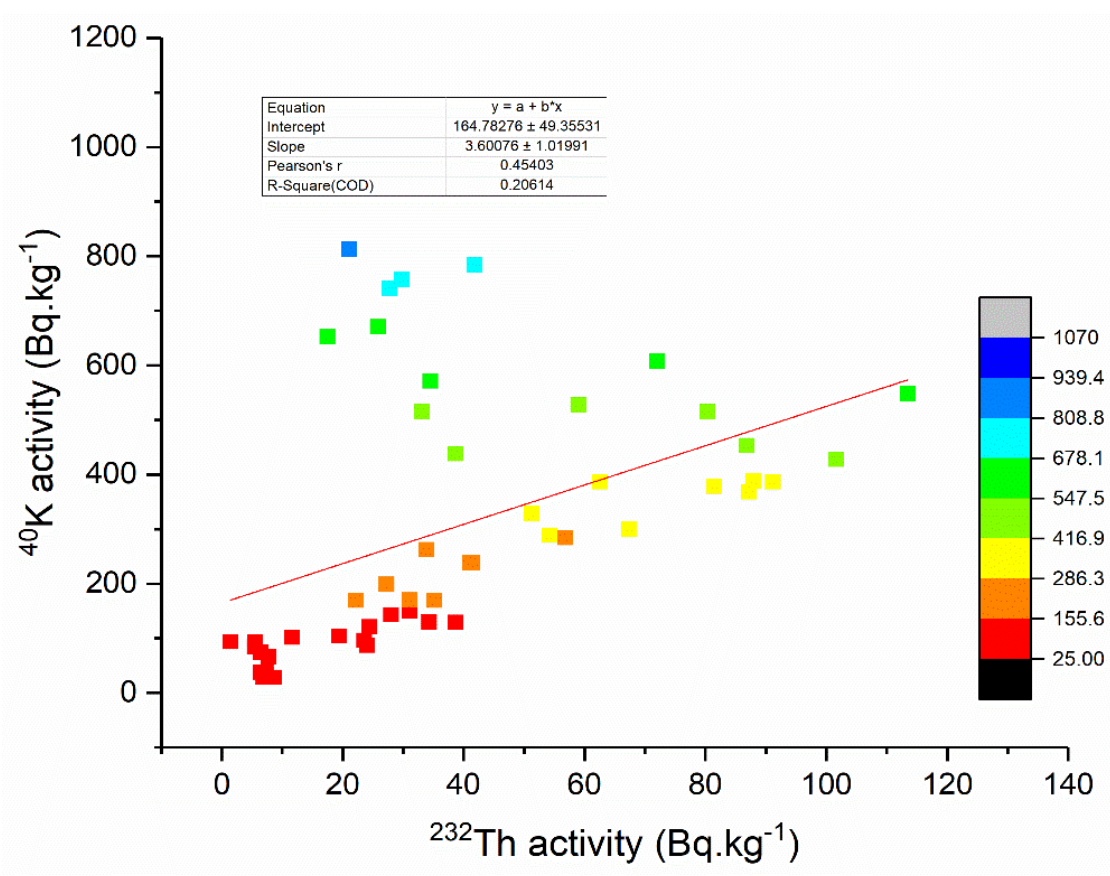

Figure 3. Correlation between of activity concentrations ${ }^{226} \mathrm{Ra}$ and ${ }^{40} \mathrm{~K}$ natural radionuclides showing colour codes for the corresponding ${ }^{40} \mathrm{~K}$ activity

\section{Conclusion}

Natural radioactivity levels in the selected building materials used in Sudan were measured using gamma spectrometry. The average values obtained are comparable to those reported in the literature. Continuous demand for both local and imported building materials necessitates regular monitoring of radioactivity levels to protect the occupants of buildings from radiation. The current data provide important radioactivity levels. Their benchmarking is the first step towards acquiring large scale data that would make it possible to set national regulatory control limits for protection of the public from radiation in buildings. These results indicate that considering the various types of dwellings constructed in various states and regions of Sudan and the variety of building materials used in their construction, establishment of a national research project to study radioactivity levels in building materials and evaluate the risk they pose to the population, is strongly recommended. Such a project should also consider investigating radon gas in dwellings and workplaces to establish safety limits to mitigate the radiological risk associated with radioactivity in building materials.

Acknowledgements. The authors would like to thank the building material workhouses for supplying us with the study samples.

Declaration of Conflicting Interests. The authors have no conflict of interests to declare.

\section{REFERENCES}

[1] Beretka, J., Mathew, P. J. (1985): Natural radioactivity of Australian building materials, industrial wastes and by-products. - Health physics 48(1): 87-95. 
[2] European Commission. Environment Directorate-General (1999): Radiological protection principles concerning the natural radioactivity of building materials. - Radiation protection No. 112, Office for Official Publications of the European Communities.

[3] ICRP (2019): ICRP Publication 142: Radiological Protection from Naturally Occurring Radioactive Material (NORM) in Industrial Processes. - Annals of the ICRP 48(4): 5-67.

[4] International atomic energy agency (IAEA) (2003): Extent of environmental contamination by naturally occurring radioactive material (NORM) and technological options for mitigation. - IAEA Technical Reports Series No. 419, Vienna.

[5] ISO, IEC, and BIPM OIML (1995): Guide to the expression of uncertainty in measurement. - Geneva, Switzerland.

[6] Mavi, B., Akkurt, I. (2010): Natural radioactivity and radiation hazards in some building materials used in Isparta, Turkey. - Radiat. Phys. Chem. 79(9): 933-937.

[7] National Research Council (NRC) (1988): Health risks of radon and other internally deposited alpha-emitters: BEIR IV (Vol. 4). - National Academies Press.

[8] NORDIC (2000): The radiation protection authorities in Denmark, Finland, Iceland, Norway and Sweden 2000. Naturally occurring radiation in the Nordic countriesrecommendations. - The Flag-Book Series, Reykjavik.

[9] Righi, S., Bruzzi, L. (2006): Natural radioactivity and radon exhalation in building materials used in Italian dwellings. - J. Environ. Radioact. 88(2): 158-170.

[10] Salih, I., Ali, S., Eisa, S., Idriss, H. (2014): Radiation exposure of workers in storage areas for building materials. - J. Taibah. Univ. Sci. 8(4): 394-400.

[11] Sam, A. K., Abbas, N. (2001): Assessment of radioactivity and the associated hazards in local and imported cement types used in Sudan. - Radiat. Prot. Dosim. 93(3): 275-277.

[12] Shayeb, M. A., Majid, A., Zobidi, S. (2017): Distribution of natural radioactivity and radiological hazard using a $\mathrm{NaI}(\mathrm{Tl})$ gamma-ray spectrometric system. - Journal of Building Physics 40(4): 324-333.

[13] Trevisi, R., Leonardi, F., Risica, S., Nuccetelli, C. (2018): Updated database on natural radioactivity in building materials in Europe. - J. Environ. Radioact. 187: 90-105.

[14] Turhan, Ş., Arıkan, I. H., Demirel, H., Güngör, N. (2011): Radiometric analysis of raw materials and end products in the Turkish ceramics industry. - Radiat. Phys. Chem. 80(5): 620-625.

[15] UNSCEAR (2000): Effects of ionizing radiation: UNSCEAR 2000 Report to the General Assembly, with scientific annexes, Vol. 2. - United Nations Scientific committee on the effects of atomic radiation, United Nations Publications. 